\title{
Deformation and Failure Characteristics of the Rock Masses around Deep Underground Caverns
}

\author{
Chong Zhang, ${ }^{1}$ Zhechao Wang, ${ }^{2}$ and Qi Wang ${ }^{2}$ \\ ${ }^{1}$ College of Electronic and Information Engineering, Henan University of Science and Technology, 263 Kaiyuandadao, \\ Luolong, Luoyang, Henan 471023, China \\ ${ }^{2}$ Geotechnical and Structural Engineering Research Center, Shandong University, 17923 Jingshi Road, Jinan, Shandong 250061, China
}

Correspondence should be addressed to Zhechao Wang; wanz@sdu.edu.cn

Received 4 May 2015; Accepted 9 July 2015

Academic Editor: Paolo Lonetti

Copyright (C) 2015 Chong Zhang et al. This is an open access article distributed under the Creative Commons Attribution License, which permits unrestricted use, distribution, and reproduction in any medium, provided the original work is properly cited.

\begin{abstract}
The deformation and failure characteristics of deep rock masses are the focus of this study on deep rock mass engineering. The study identifies the deformation and failure characteristics of a deep cavern under different ground stress conditions using model test and theoretical analysis methods. First, the similarity theory for model tests is introduced, and then the scale factors used in the present study are calculated according to the Froude criterion. Based on the study objectives, the details of the study methods (the similarity coefficient, the loading conditions, the test steps, etc.) are introduced. Finally, the failure characteristics of the deep cavern and the strain distribution characteristics surrounding the caverns under different ground stress conditions are identified using the model test. It was found that compared with shallow rock masses the rock masses of the deep cavern have a much greater tensile range, which reaches 1.5 times the diameter of the cavern under the conditions established in the present study. Under different ground stress conditions, there are differences in failure characteristics and the reasons of the differences were analyzed. The implication of the test results on the design of support system for deep caverns was presented.
\end{abstract}

\section{Introduction}

The construction of infrastructure such as hydropower stations and the deep exploitation of such energy resources as coal require us to understand the deformation and failure characteristics of deep underground caverns. The high ground stress states in deep rock masses have a great effect on the stability of the rocks surrounding caverns. After the excavation of a cavern is completed, readjustment of the high ground stress states in the rock masses will occur; stress redistribution often leads to stress concentration, resulting in the development of pressure on the rocks surrounding the lining or the support system of the deep underground engineering structure. When the pressure on the rocks surrounding a cavern exceeds the strength limit or the yield limit of the rock masses, plastic deformation or failure will occur in the rocks surrounding the cavern.

Currently, there are many theories regarding the relation between the depth of a cavern and the pressure of the rocks surrounding the cavern. In some equations, the pressure of the rocks surrounding a cavern is unrelated to the depth of the cavern; in other equations, however, the pressure of the rocks surrounding a cavern is related to the depth of the cavern. The current study shows that when the rocks surrounding a cavern are in a plastic deformation state, the embedded depth of the cavern is greater, and the pressure of the rocks surrounding the cavern is higher. The rocks surrounding a deep cavern are often in a high plastic state; thus, the pressure of the rocks surrounding the cavern increases with the increasing depth [1-3]. Rock masses with different properties will have different failure modes under high pressure from the surrounding rocks $[4,5]$.

Researchers from many countries have observed the failures of deep rock masses surrounding deep caverns [6], for example, the deep caverns in the metal mines in South Africa and Russia and the Jinchuan nickel mines in China. Based on the drilling data for the rocks surrounding a deep cavern and the comprehensive sectional view obtained 
from the drilling data, Shemyakin et al. developed the basic pattern of the failure phenomenon of deep surrounding rocks and noted that such a failure mode is quite different from the deformation and failure state of the original shallow surrounding rocks [7]. Guzev and Paroshin attempted to understand the nonmonotonic variation pattern of the stress related to the distance from the surface of the cavern using the non-Euclidean geometric model and discovered that such nonmonotonicity was related to the attenuation of the stress field along the cavern or the periodic variation of stress with time [8]. Metlov et al. revealed the physical basis of the alternating disintegration near the cavern from the perspective of equilibrium thermodynamics [9]. These authors described the instability evolution of the rocks from their elastic state when the cavern was excavated to their mature alternating disintegrated structure and simulated such a relation in a numerical experiment; however, Metlov et al. could not explain the mechanism and condition of the occurrence of such a relation. Reva analyzed the stability of zonally disintegrated surrounding rocks using the energy criterion [10]. Diederichs et al. analyzed the failure process of brittle rocks and concluded that tensile failure was the dominant failure mode during the damage and failure processes of brittle rocks and that the main cause for the final failure (splitting or the formation of a shear zone) was the development, accumulation, and interaction of tensile failure [11]. Zhou et al. analyzed the mechanism of the zonal disintegration of the rocks surrounding a deeply buried spherical cavern [12]. Li et al. conducted an analysis of the fracture form of the rocks surrounding a deeply buried tunnel during the excavation process [13]. Li et al. analyzed the mechanism of the occurrence of the zonal disintegration phenomenon of rock masses [14].

In terms of study methods, test studies on the failure of deep rock masses can be classified into two types: field test studies and model test studies. These two types of test studies have common characteristics: knowledge of patterns is derived from large amounts of test data, and the effects of some factors on the failure of deep rock masses are directly evaluated [4]. Field full-prototype-scale tests are advantageous in that they have visual results and phenomena and the test results can be used directly [6]. Physical simulation tests are an effective, economical, and important manner in which we study deep underground engineering structures. A physical model is a real physical entity. When the model satisfies the basic similarity principle, a physical model can preclude mathematical and mechanical difficulties and relatively truly, comprehensively, visually, and accurately reflect the overall mechanical characteristics, deformation trend, and stability characteristics of the rocks surrounding a deep underground engineering structure [4]. The results obtained from a physical model and the results obtained from numerical calculation or theoretical analysis can be mutually verified; a physical model can also be utilized to discover new mechanical phenomena and patterns to provide important bases for establishing new calculation theories and mathematical models.

In the present study, the deformation and failure characteristics of a deep cavern under different ground stress conditions are obtained using model test and theoretical analysis methods. The similarity theory for model tests is introduced first, and the scale factors used in the present study are calculated according to the Froude criterion. Then, based on the study objectives, the details of the study method (the similarity coefficient, the loading conditions, the test procedure, etc.) are introduced. Finally, the failure characteristics of the deep cavern as well as the strain distribution characteristics surrounding the cavern under different ground stress conditions are developed utilizing the model test. The research results can provide a basis for designing support systems for deep caverns.

\section{Similarity Theory}

Similarity theory is the theoretical basis for model tests. The results of a model test that satisfies similarity conditions can better reflect the actual conditions of the prototype. Whether the results of a model test can reflect the actual conditions of a prototype and provide a qualitative or quantitative design basis for the prototype depends on the degree of similarity between the model test and the physical process of the prototype [15].

Currently, there is no established mathematical equation for characterizing the entire failure process of the rocks surrounding a deep cavern. It is therefore necessary to first study the similarity criteria using the dimensional analysis method. According to dimensional analysis, for a rock mass medium, the possible physical phenomena $(Q)$ of a model test are primarily related to the following physical quantities.

The following are the parameters of the rock mass medium: density $(\rho)$, elastic modulus $(E)$, compressive strength $\left(R_{C}\right)$, tensile strength $\left(R_{t}\right)$, Poisson's ratio $(v)$, cohesion $(c)$, and internal friction angle $(\Phi)$. The geometric dimensional parameters of the cavern are as follows: span $(D)$, height $(H)$, and radius of the arch $(R)$.

According to dimensional theory, among the physical quantities that describe physical phenomena, length, time, and mass can generally be selected as the basic physical quantities, and other physical quantities can be considered derived quantities (Table 1). For instance, length $(l)$ is a physical quantity with a dimension of L, density $(\rho)$ is a physical quantity with a dimension of $\mathrm{ML}^{-3}$, and acceleration (a) is a physical quantity with a dimension of $\mathrm{LT}^{-2}$.

According to the basic scale law, the scale factor of each of the abovementioned physical quantities can be expressed using the scale factors of the quantities in its dimension instead of simply using the quantities in its dimension. Thus, the following relations can be derived:

$$
\begin{aligned}
& K_{l}=K_{l}, \\
& K_{\rho}=K_{m} \cdot K_{l}^{-3}, \\
& K_{a}=K_{l} \cdot K_{t}^{-2},
\end{aligned}
$$

where $K_{l}, K_{\rho}, K_{a}, K_{m}$, and $K_{t}$ in the above equations are all the scale factors of the quantities of the same type of model and 
TABLE 1: Scale factors and dimensions of the main variables.

\begin{tabular}{lcc}
\hline Variables & Scale factors & Dimensions \\
\hline Length & $K_{l}$ & $\mathrm{~L}$ \\
Density & $K_{\rho}$ & $\mathrm{ML}^{-3}$ \\
Acceleration & $K_{a}$ & $\mathrm{LT}^{-2}$ \\
Time & $K_{t}$ & $\mathrm{~T}$ \\
Stress & $K_{\sigma}$ & $\mathrm{ML}^{-1} \mathrm{~T}^{-2}$ \\
Strain & $K_{\varepsilon}$ & - \\
Poisson's ratio & $K_{\mu}$ & - \\
Friction angle & $K_{\phi}$ & - \\
Velocity & $K_{V}$ & $\mathrm{LT}^{-1}$ \\
Force & $K_{F}$ & $\mathrm{MLT}^{-2}$ \\
Specific weight & $K_{\gamma}$ & $\mathrm{ML}^{-2} \mathrm{~T}^{-2}$ \\
Impulse & $K_{i}$ & $\mathrm{MLT}^{-1}$ \\
Energy & $K_{E}$ & $\mathrm{ML}^{2} \mathrm{~T}^{-2}$ \\
\hline
\end{tabular}

the prototype. Based on (2) and (3), the following equation can be derived:

$$
\begin{aligned}
K_{m} & =K_{\rho} \cdot K_{l}^{3}, \\
K_{t} & =K_{l}^{1 / 2} \cdot K_{a}^{-1 / 2} .
\end{aligned}
$$

The dimension of any variable can be expressed using the power product of $\mathrm{M}, \mathrm{L}$, and $\mathrm{T}$. In addition, the scale factors of $\mathrm{M}, \mathrm{L}$, and $\mathrm{T}$ can be expressed using the scale factors $\left(K_{l}\right.$, $K_{\rho}$, and $K_{a}$ ) of the 3 selected independent variables (length, density, and acceleration). Therefore, the scale factor of any variable can also be expressed using the scale factors $\left(K_{l}, K_{\rho}\right.$, and $K_{a}$ ) of the 3 selected independent variables.

A geomechanical model test must comply with the related similarity relation criteria. The following criterion is the most important strength relation criterion that must be complied with:

$$
K_{\sigma}=K_{l} \cdot K_{\rho} \cdot K_{g}
$$

where $K_{\sigma}=\sigma_{m} / \sigma_{p}$ represents the ratio of the compressive strength of the model to the compressive strength of the prototype, $K_{l}=l_{m} / l_{p}$ represents the ratio of the geometric dimension of the model to the geometric dimension of the prototype, $K_{\rho}=\rho_{m} / \rho_{p}$ represents the ratio of the density of the material of the model to the density of the material of the prototype, and $K_{g}=g_{m} / g_{p}$ represents the ratio of the acceleration of the model body to the acceleration of the prototype body. Table 2 lists the scale factors of the variables.

It is extremely difficult to satisfy the numerous parameter similarity requirements in one test. Hence, it is necessary to perform proper simplification according to the test objective and the principles according to which the main issues should be stressed. According to the Froude scaling requirements, the material of a model should satisfy the following relations:

(i) The material of a model should have the quantities of the dimension of the stress: $K_{\sigma}=K_{\rho} \cdot K_{l}$.

(ii) Strain: $K_{\varepsilon}=1$.
TABLE 2: Scale factors of the variables.

\begin{tabular}{lcc}
\hline Variables & Scale factors & Froude scale factors \\
\hline Length & $K_{l}$ & $K_{l}$ \\
Density & $K_{\rho}$ & $K_{\rho}$ \\
Acceleration & $K_{a}$ & $K_{a}=1$ \\
Time & $K_{t}=K_{l}^{1 / 2} \cdot K_{a}^{-1 / 2}$ & $K_{t}=K_{l}^{1 / 2}$ \\
Stress & $K_{\sigma}=K_{\rho} \cdot K_{a} \cdot K_{l}$ & $K_{\sigma}=K_{\rho} \cdot K_{l}$ \\
Strain & $K_{\varepsilon}$ & $K_{\varepsilon}=1$ \\
Poisson's ratio & $K_{\mu}$ & $K_{\mu}=1$ \\
Friction angle & $K_{\phi}$ & $K_{\phi}=1$ \\
Velocity & $K_{V}=K_{a}^{1 / 2} \cdot K_{l}^{1 / 2}$ & $K_{V}=K_{l}^{1 / 2}$ \\
Force & $K_{F}=K_{\rho} \cdot K_{a} \cdot K_{l}^{3}$ & $K_{F}=K_{\rho} \cdot K_{l}^{3}$ \\
Specific weight & $K_{\gamma}=K_{\rho} \cdot K_{a}$ & $K_{\gamma}=K_{\rho}$ \\
Impulse & $K_{i}=K_{\rho} \cdot K_{a} \cdot K_{l}^{7 / 2}$ & $K_{i}=K_{\rho} \cdot K_{l}^{7 / 2}$ \\
Energy & $K_{w}=K_{\rho} \cdot K_{a} \cdot K_{l}^{4}$ & $K_{w}=K_{\rho} \cdot K_{l}^{4}$ \\
\hline
\end{tabular}

(iii) Poisson's ratio: $K_{\mu}=1$.

(iv) Friction angle: $K_{\phi}=1$.

In addition, the actual engineering is extremely complex; thus, it is relatively difficult to completely, comprehensively, and truly simulate actual situations. The following simplification assumptions are made when designing the model test:

(1) Only the effect of the ground stress field is considered; the effect of the dead weight of the surrounding rocks near the walls of the cavern is not considered.

(2) Rock masses are homogeneous; the effect of the tectonic structures (e.g., bedding and joints) is not considered.

(3) Considerations are not based strictly on the rheological similarity conditions of each material; however, errors caused by reading intervals are avoided.

\section{Research Method}

3.1. Similarity Coefficients of the Model Test. Geometric similarity conditions and stress similarity conditions are primarily considered based on the similarity issue of the model test of the present research project.

3.1.1. Geological Conditions. The prototype cavern has a buried depth $(H)$ of $1,000 \mathrm{~m}$ and a rock mass density $(\rho)$ of $2.4 \times 10^{3} \mathrm{~kg} / \mathrm{m}^{3}$. The vertical initial ground stress load $\left(P_{V}{ }^{0}\right)$ that is generated by the dead weight of the rock masses is $24.0 \mathrm{MPa}$. The side pressure coefficient $(N)$ is $1 / 3$. Therefore, the horizontal ground stress load $\left(P_{h}^{0}\right)$ that is generated by the dead weight of the rock masses is $8.0 \mathrm{MPa}$. According to the national standard classification method for surrounding rocks, type II rock masses are selected. Type II rock masses have a uniaxial compressive strength of $30 \mathrm{MPa} 60 \mathrm{MPa}$. In the present study, type II rock masses with a uniaxial compressive strength of $40 \mathrm{MPa}$ are selected. Caverns with straight walls and an arch vault, which are commonly used in underground engineering, have a span 
TABLE 3: Mechanical parameters of the original rock masses and the material of the physical model.

\begin{tabular}{|c|c|c|c|c|c|c|c|}
\hline $\begin{array}{l}\text { Types of } \\
\text { surrounding rocks }\end{array}$ & $\begin{array}{c}\text { Compressive } \\
\text { strength } \\
(\mathrm{Rc})(\mathrm{MPa})\end{array}$ & $\begin{array}{c}\text { Tensile } \\
\text { strength } \\
\text { (Rt) }(\mathrm{MPa})\end{array}$ & $\begin{array}{l}\text { Cohesion } \\
\text { (C) }(\mathrm{MPa})\end{array}$ & $\begin{array}{c}\text { Internal } \\
\text { friction angle } \\
(\varphi)\left({ }^{\circ}\right)\end{array}$ & $\begin{array}{l}\text { Deformation } \\
\text { modulus } \\
(\mathrm{Em})(\mathrm{GPa})\end{array}$ & $\begin{array}{l}\text { Poisson's } \\
\text { ratio }(\mu)\end{array}$ & $\begin{array}{c}\text { Density }(\rho) \\
\quad\left(\mathrm{kg} / \mathrm{m}^{3}\right)\end{array}$ \\
\hline Original rock II & 40 & 2.7 & 2.0 & 50 & 20 & 0.25 & 2400 \\
\hline $\begin{array}{l}\text { Required } \\
\text { simulation material }\end{array}$ & 2.0 & 0.14 & 0.1 & 50 & 1.0 & 0.25 & 1.8 \\
\hline $\begin{array}{l}\text { Selected simulation } \\
\text { material }\end{array}$ & 2.28 & 0.3 & 0.8 & 54 & 0.63 & 0.25 & 1.8 \\
\hline
\end{tabular}

(D) of 3,000 $\mathrm{mm} \sim 5,000 \mathrm{~mm}$. In the present study, a cavern with a span of $3,000 \mathrm{~mm}$, a sidewall height of $1,500 \mathrm{~mm}$, and a vault height of $1,500 \mathrm{~mm}$ were selected.

3.1.2. Dimension of the Model Cavern. The present study avoids the effect of the loading boundary of the model test device on the force on the inside of the model cavern and the effect of the boundary of the cavern on the force on the boundary of the model body. Theoretically, if the dimension of a model body is larger, the dimension of the cavern is smaller, and the interaction between the boundary of the model body and the boundary of the cavern is smaller. However, if the model body is too large, the test workload will be large, and the test period will be long. If the dimension of the cavern is too small, construction simulation will be difficult to conduct, and the requirements for testing and excavation techniques will be high. The test model used in the present study has a length of $1,000 \mathrm{~mm}$, a width of $1,000 \mathrm{~mm}$, and a thickness of $400 \mathrm{~mm}$. Plane strain sections are perpendicular to the axial direction of the cavern. If the span of the model cavern is $200 \mathrm{~mm}$, the length and width of the model body will be 5 times the span of the cavern; thus, the related theoretical requirements are met, and there will be no interaction between the boundary of the model body and the boundary of the cavern. Therefore, the geometric similarity coefficient is $1: 15$, and a span of $200 \mathrm{~mm}$ is selected as the span of the model cavern. Figure 1 shows the dimension of the model cavern.

3.1.3. Selection of the Material of the Model. A stress similarity coefficient of 1:20 was selected. Low-grade cement mortar with a weight ratio of cement : sand : water of $1: 14: 1.4$ was selected as the rock mass simulation material. The tamping method was used for molding the cement mortar. The material of the model has a compressive strength of 2.28 MPa. Table 3 lists the detailed mechanical parameters of the original rock, the required simulation material, and the selected simulation material.

3.2. Loading Conditions. The objective of this set of tests is to obtain the maximum test load and failure mode of the cavern with straight walls and an arch vault under different ground stress load conditions when there is plane strain and the side pressure coefficient is $1 / 3$. The test cavern is a cavern with straight walls and an arch vault. The ground stress load for M1 is of the same order of magnitude as the uniaxial compressive

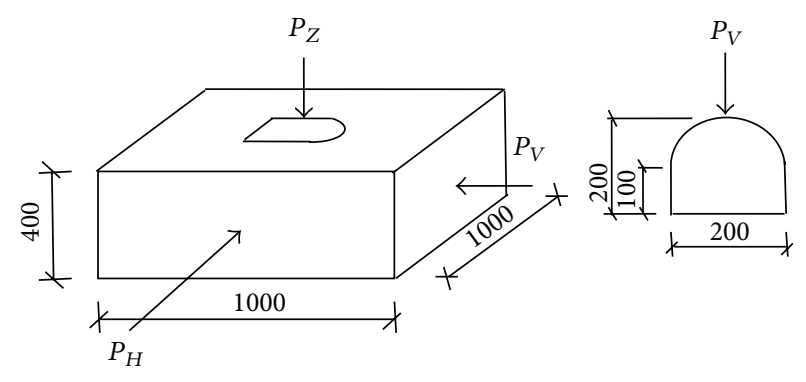

FIGURE 1: Dimensions of the section of the prototype cavern.

strength of the material of the model; the ground stress load for $\mathrm{M} 2$ is 2.17 times the uniaxial compressive strength of the material of the model.

\subsection{Test Steps}

(1) The ground stress load is evenly applied in 8 steps.

(2) After the application of the ground stress load is completed, full-section excavation of the cavern begins; the excavation is completed in 4 steps. The failure of the cavern begins during the excavation process. To ensure the formation of the cavern, the rapid excavation method is used. The excavation of the next level begins immediately after each step of excavation is completed without carefully trimming the external shape of the cavern.

\section{Test Results}

\subsection{M1 Test Results}

4.1.1. Failure Conditions of the M1 Cavern. Figure 2 shows the macroscopic failure conditions of the cavern. The following are apparent in the figure:

(i) The failure of the cavern occurs at the sidewalls but not at the vault or the floor.

(ii) All of the cracks in the sidewalls develop upwards from the junctions between the sidewalls and the floor in the forms of parabolas and clusters and basically disappear at locations that are level with the feet of the vault. 


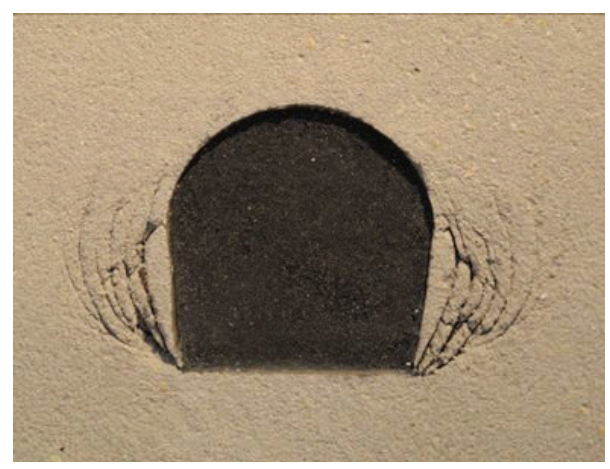

FIGURE 2: Image of the macroscopic failure of the M1 model.

(iii) There are 6 cracks in each of the left and right sidewalls; the degrees of damage to the left and right sidewalls are basically identical.

(iv) With the exception of the cracked body between the first crack and the sidewall, which is relatively wide, all of the other cracked bodies between the cracks are relatively narrow. The width of the cracked body gradually increases as the distance from the sidewall increases.

(v) An obliquely downward crack from the foot of the vault in the left sidewall of the cavern intersects the 4 cracks that are adjacent to the wall of the cavern. An obliquely downward crack from the foot of the vault in the right sidewall of the cavern and an obliquely downward crack from the center of the right sidewall intersect the 5 cracks that are adjacent to the right sidewall.

4.1.2. Changes in the Dimension of the Section of the Cavern. The height of the cavern decreases from $200 \mathrm{~mm}$ to $194 \mathrm{~mm}$ (a $6 \mathrm{~mm}$ decrease), the span of the floor of the cavern decreases from $200 \mathrm{~mm}$ to $160 \mathrm{~mm}$ (a $40 \mathrm{~mm}$ decrease), the span between the centers of the two sidewalls decreases from $200 \mathrm{~mm}$ to $180 \mathrm{~mm}$ (a $20 \mathrm{~mm}$ decrease), and the span between the left foot of the vault and the right foot of the vault decreases from $200 \mathrm{~mm}$ to $185 \mathrm{~mm}$ (a $15 \mathrm{~mm}$ decrease) (Figure 3).

The following may also be observed from the above measurement data:

(i) The entire cavern shrinks. Under the plane strain conditions along the axial direction of the cavern, the shrinkage of the dimension is relatively small in the direction in which the load is relatively large (the vault-floor direction); the shrinkage of the dimension is relatively large in the direction in which the load is relatively small (the left sidewall-right sidewall direction).

(ii) No significant deformation of the vault and the floor of the cavern is observed. The left and right sidewalls are severely deformed. The shrinkage gradually increases from the junction between each sidewall and the respective foot of the vault to the junction

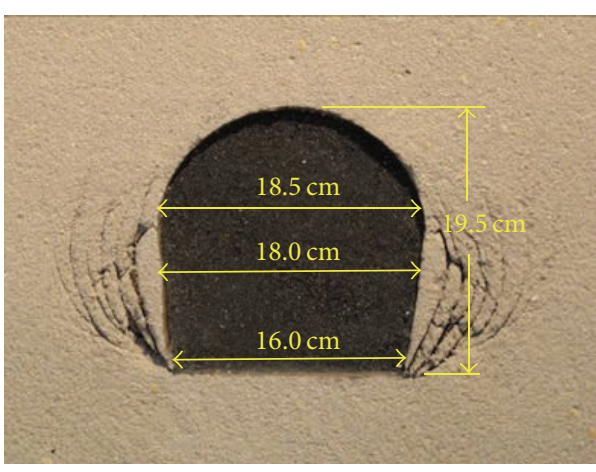

FIGURE 3: Change in the dimensions of the section of the M1 model cavern.

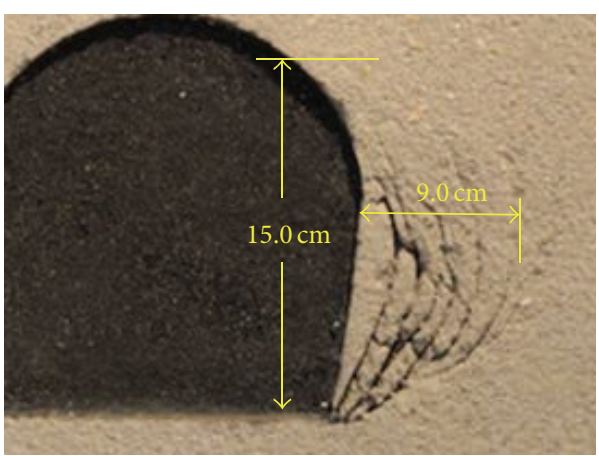

FIGURE 4: Width and height of the cracks in the right sidewall of the M1 model.

between each sidewall and the floor. The lower portion of the section of the cavern exhibits an inverted trapezoid shape.

4.1.3. Crack Ranges. The widest section of the cracks in the left sidewall is level with the foot of the vault; the distribution width is $90 \mathrm{~mm}$ from the foot of the vault outwards; the cracks are $140 \mathrm{~mm}$ high; and the cracked bodies are $3 \mathrm{~mm} 20 \mathrm{~mm}$ wide.

The widest section of the cracks in the right sidewall is level with the foot of the vault; the distribution width is $90 \mathrm{~mm}$ from the foot of the vault outwards; the cracks have a height of $150 \mathrm{~mm}$; and the cracked bodies have a width ranging from $3 \mathrm{~mm}$ to $20 \mathrm{~mm}$ (Figure 4).

The distribution width of the cracks is smaller than the distribution height of the cracks.

4.1.4. Strain Test Results. Figures 5 and 6 show the values of the radial and circumferential strains inside the medium above the vault, respectively, after the excavation is completed. In the present study, tensile strains are positive, and compressive strains are negative (the same is true for the M2 test).

\section{(1) Radial Strains}

(i) The radial support decreases with the radial strains on the vault, and the absolute values of the radial 


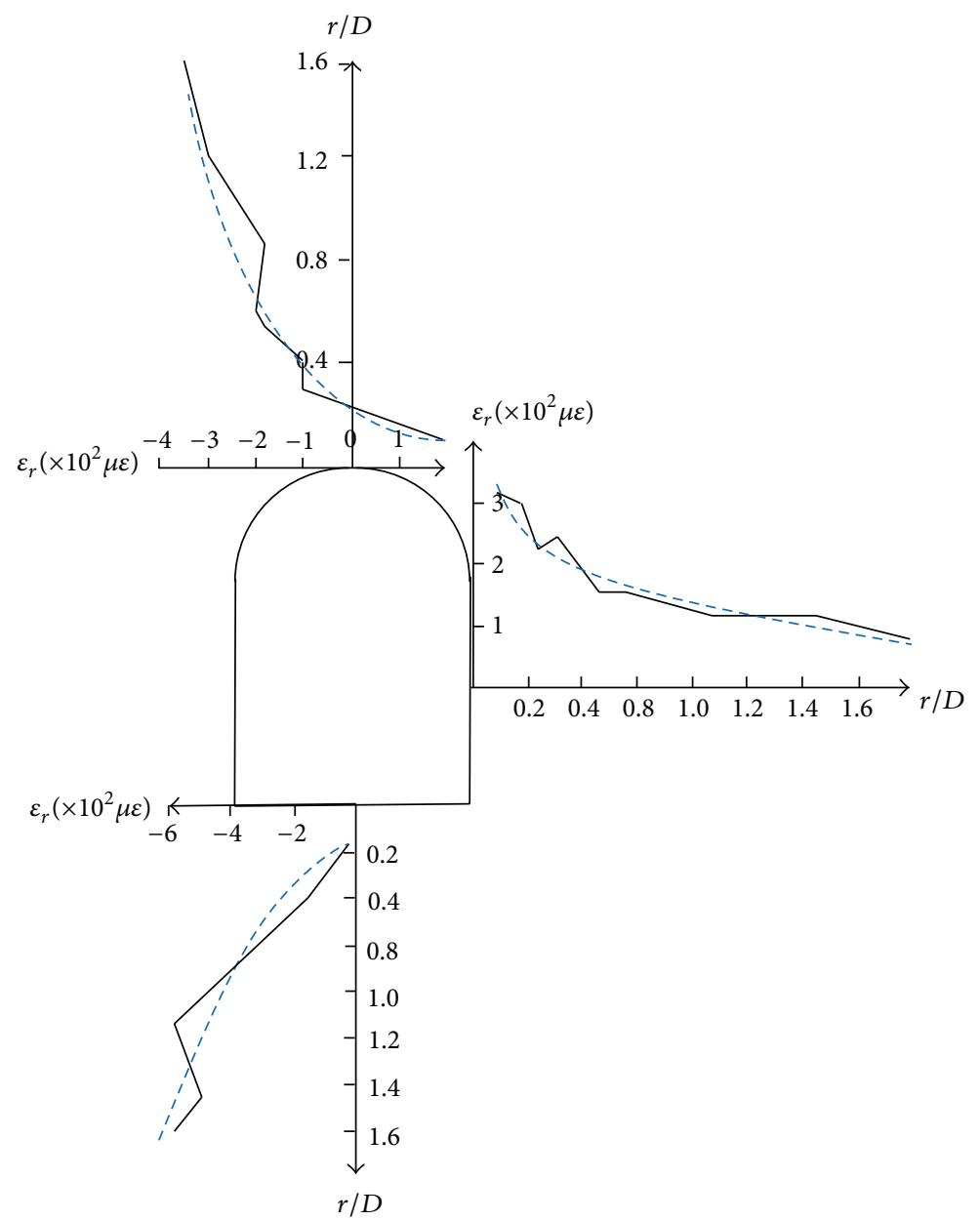

Figure 5: Radial strain curve of the M1 model cavern.

strains also decrease as the distance from the wall of the cavern increases. Compressive strains change to tensile strains at the locations near the wall of the cavern.

(ii) The radial strains on each of the two sidewalls are tensile strains and gradually increase as the distance from the sidewall decreases. After the excavation is completed, the value of the radial tensile strain on each of the two sidewalls is 3.6 times the value of the tensile strain at the measurement point that is farthest from the wall of the cavern.

(iii) The radial strains inside the model on the bottom of the floor are compressive strains and decrease as the distance from the floor decreases. The value of the radial compressive strain at the measurement point that is farthest from the floor is 12.2 times the value of the radial compressive strain at the measurement point closest to the floor.

\section{(2) Circumferential Strains}

(i) The restricting effect of the surrounding rocks on the circumferential strains on the vault decreases as the distance from the walls of the cavern decreases, resulting in an increase in the values of the circumferential strains on the vault as the distance from the walls of the cavern decreases.

(ii) The value of the circumferential compressive strain on each of the sidewalls is 2.0 times the value of the compressive strain at the measurement point that is farthest from the sidewall, indicating that the degrees of the variations of the values of the radial tensile strains on each of the sidewalls are greater than the values of the circumferential compressive strains on each of the sidewalls as the distance from the sidewall decreases.

(iii) The circumferential strains inside the model on the floor are basically compressive strains and gradually increase as the distance from the floor decreases. For example, the value of the circumferential strain at the measurement point that is relatively close to the floor is 2.1 times the value of the circumferential strain at the measurement point that is farthest from the floor. The variation pattern of the circumferential strain begins changing at the location that is relatively close to the floor; the circumferential strain changes from a 


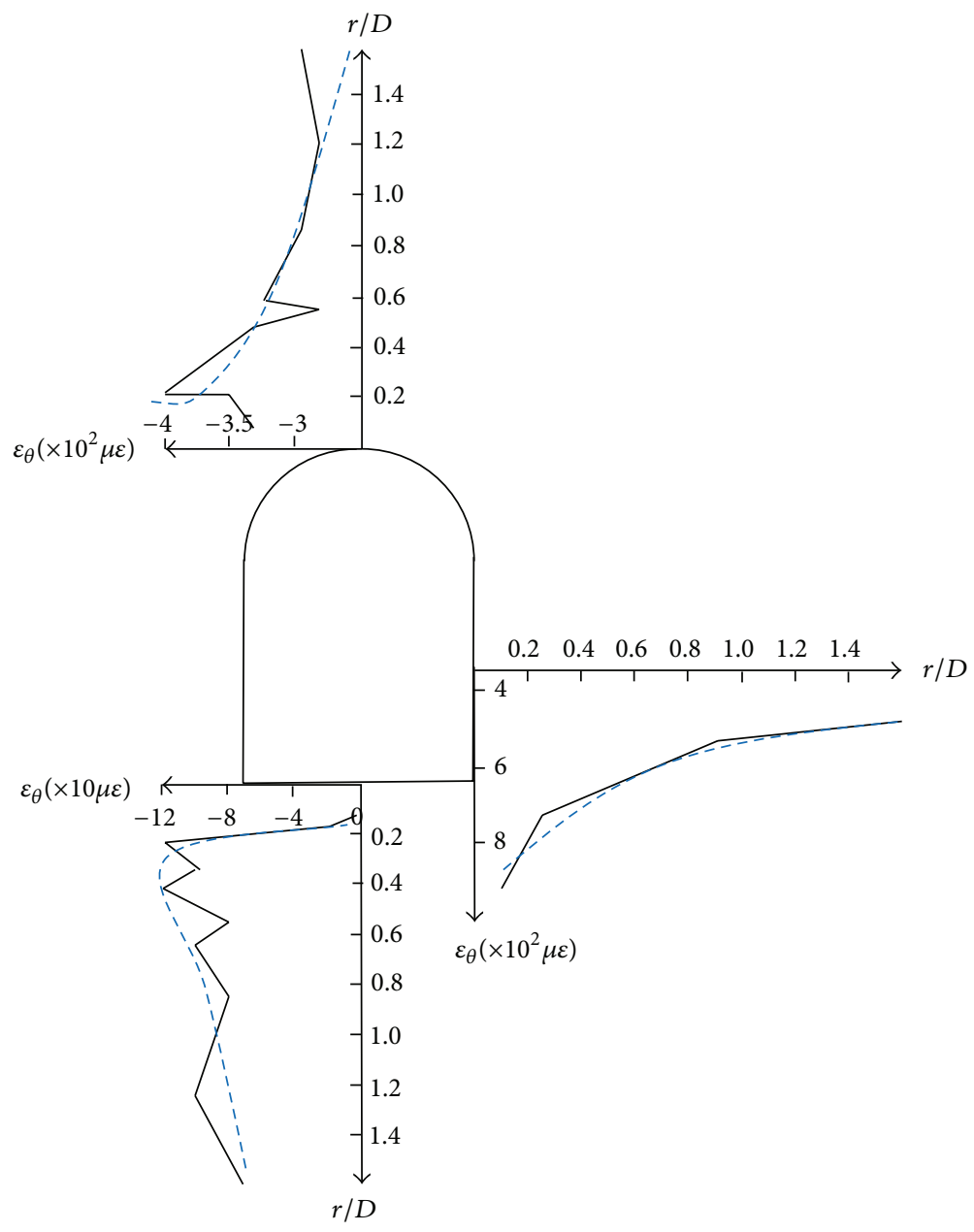

Figure 6: Circumferential strain curve of the M1 model cavern.

circumferential compressive strain to a circumferential tensile strain.

\subsection{M2 Test Results}

4.2.1. Failure Conditions of the M2 Cavern. Figure 7 shows the macroscopic failure of the cavern. The figure shows the following:

(i) The failure of the cavern occurs at the sidewalls but not at the vault or the floor.

(ii) All the cracks in the sidewalls develop upwards from the junctions between the sidewalls and the floor in the forms of parabolas and clusters and basically disappear at locations that are level with the foot of the vault.

(iii) There are 6 cracks in each of the left and right sidewalls; the degrees of damage to the left and right sidewalls are basically identical.

(iv) The cracked body between the second and the third cracks and the cracked body between the third and the fourth cracks in the left sidewall are relatively narrow; the cracked body between the second and the third cracks in the right sidewall is relatively narrow.

(v) The 2 obliquely downward cracks from the foot of the vault in the left sidewall of the cavern intersect the cracks in the left sidewall. The 2 obliquely downward cracks from the foot of the vault in the right sidewall of the cavern and the 2 obliquely downward cracks from the center of the right sidewall intersect the cracks in the right sidewall. An obliquely downward crack from the top of the cracked body between the right sidewall and the first crack intersects the second cracked body.

4.2.2. Dimensions of the Section of the Cavern. The height of the cavern decreases from $200 \mathrm{~mm}$ to $195 \mathrm{~mm}$ (a $5 \mathrm{~mm}$ decrease), the span of the floor of the cavern decreases from $200 \mathrm{~mm}$ to $150 \mathrm{~mm}$ (a $50 \mathrm{~mm}$ decrease), the span between the centers of the two sidewalls decreases from $200 \mathrm{~mm}$ to $170 \mathrm{~mm}$ (a $30 \mathrm{~mm}$ decrease), and the span between the left and right feet of the vault decreases from $200 \mathrm{~mm}$ to $180 \mathrm{~mm}$ (a $20 \mathrm{~mm}$ decrease) (Figure 8). 


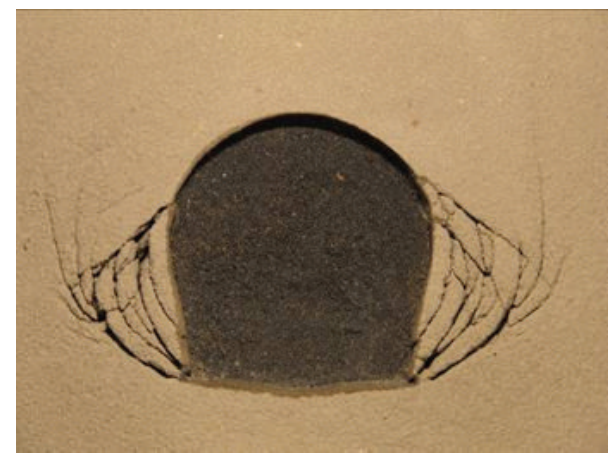

FIGURE 7: Image of the macroscopic failure of the M2 model.

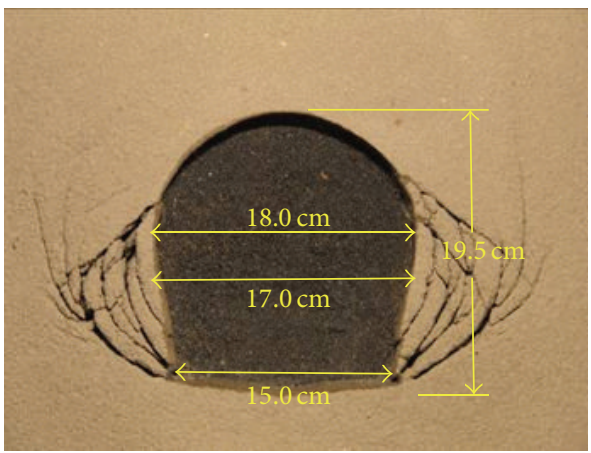

Figure 8: Change in the dimensions of the section of the M2 model cavern.

The above-mentioned measurement data also show the following:

(i) The entire cavern shrinks. Under the plane strain conditions along the axial direction of the cavern, the shrinkage of the dimension is relatively small $(5 \mathrm{~mm})$ in the direction in which the load is relatively large (the vault-floor direction); the shrinkage of the dimension is relatively large $(50 \mathrm{~mm})$ in the direction in which the load is relatively small (the left sidewallright sidewall direction).

(ii) No significant deformation of the vault and the floor of the cavern was observed. The left and right sidewalls are severely deformed. The shrinkage gradually increases from the junction between each sidewall and the respective foot of the vault to the junction between each sidewall and the floor. The lower portion of the section of the cavern exhibits an inverted trapezoid shape.

\subsubsection{Crack Ranges}

(i) The junctions between the cracks along the obliquely downward direction from each foot of the vault and the cracks along the obliquely upward direction from the bottom of the floor have an average width of $85 \mathrm{~mm}$ (Figure 9).

(ii) The left crack that is on the same horizontal level as the left foot of the vault is $85 \mathrm{~mm}$ from the left foot of

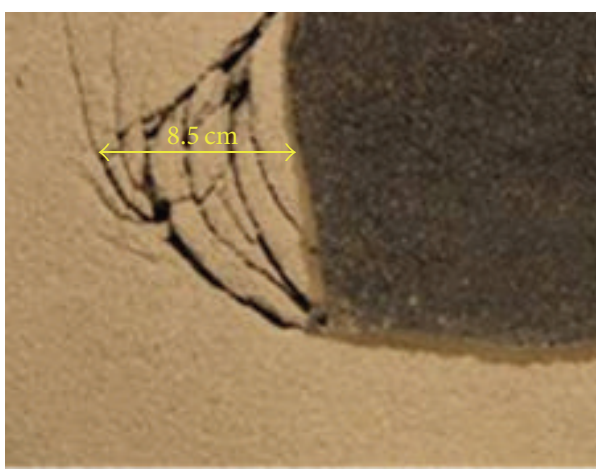

Figure 9: Width of the cracks in the left sidewall of the M2 model cavern.

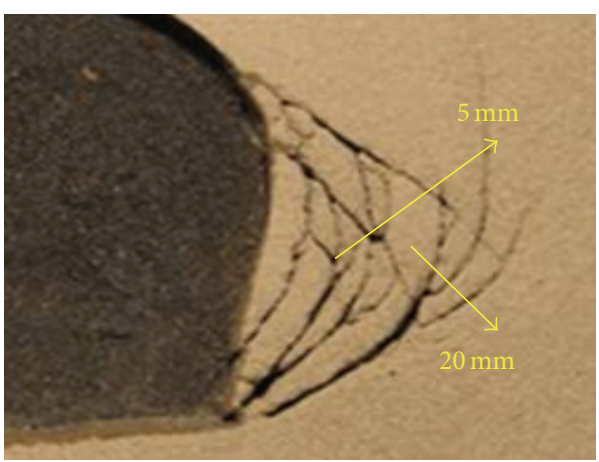

FIGURE 10: Range of the widths of the cracked bodies in the M2 model cavern.

the vault horizontally; similarly, the right crack that is on the same horizontal level with the right foot of the vault is also $85 \mathrm{~mm}$ from the right foot of the vault horizontally.

(iii) The widths of the cracked bodies range from $5 \mathrm{~mm}$ to $20 \mathrm{~mm}$ (Figure 10).

4.2.4. Strain Test Results. Figures 11 and 12 show the radial and circumferential strain values inside the medium above the vault, respectively, after the excavation is completed.

\section{(1) Radial Strains}

(i) The radial strains inside the model body on the top of the vault are all compressive strains; the values of the radial compressive strains increase as the distance from the vault increases; when compared to M1, the values of the radial compressive strains of M2 are much greater than the values of M1 at the corresponding locations.

(ii) The radial strains on the sidewalls are all tensile strains; the values of the tensile strains decrease rapidly as the distance from the sidewall increases; when compared to M1, the values of the radial tensile strains of M2 are much greater than the values of M1 at the corresponding locations.

(iii) The radial strains inside the model body on the bottom of the floor are all compressive strains; the 


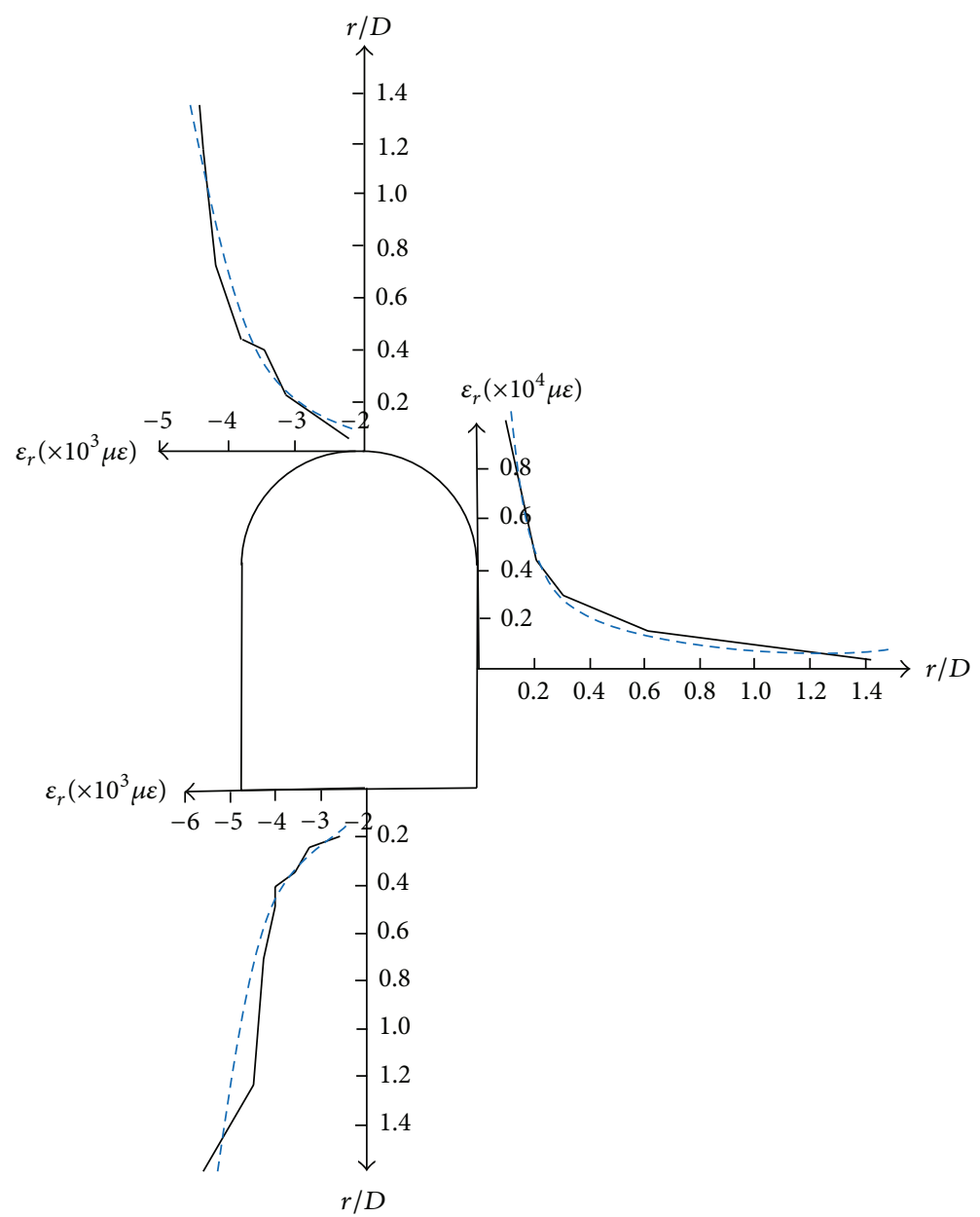

FIGURE 11: Radial strain curve of the M2 model cavern.

values of the compressive strains increase as the distance from the floor increases; when compared to $\mathrm{M} 1$, the values of the radial strains of M2 are much greater than the values of M1 at the corresponding locations.

\section{(2) Circumferential Strains}

(i) The circumferential strains inside the model body on the top of the vault are also all compressive strains; the values of the circumferential compressive strains increase as the distance from the vault increases although the degrees of the increases in the values of the circumferential strains are significantly smaller than the values of the radial strains. When compared to $\mathrm{M} 1$, the values of the circumferential strains of M2 are greater than the values of M1 at the corresponding locations although the degrees of the increases in the values of the circumferential strains are relatively small. The absolute values of the radial strains are greater than the values of the circumferential strains at the corresponding locations.

(ii) The circumferential strains on the sidewalls are compressive strains; the values of the compressive strains decrease as the distance from the sidewall increases although the degrees of the decreases in the values of the circumferential strains are significantly smaller than the values of the radial strains; when compared to M1, the values of the circumferential strains of M2 are significantly greater than the values of $\mathrm{M} 1$ at the corresponding locations.

(iii) The circumferential strains inside the model body on the bottom of the floor are compressive strains; however, there is no significant change in the values of the strains as the distance from the floor increases; when compared to M1, the values of the circumferential strains of M2 are significantly greater than the values of $\mathrm{M} 1$ at the corresponding locations. The values of the radial strains are greater than the values of the circumferential strains at the corresponding locations.

\section{Analysis of the Test Results}

5.1. Deformation and Failure Characteristics of Deep Rock Masses. Based on the analysis of the test data, we know that the rock masses of the deep cavern have a tensile 


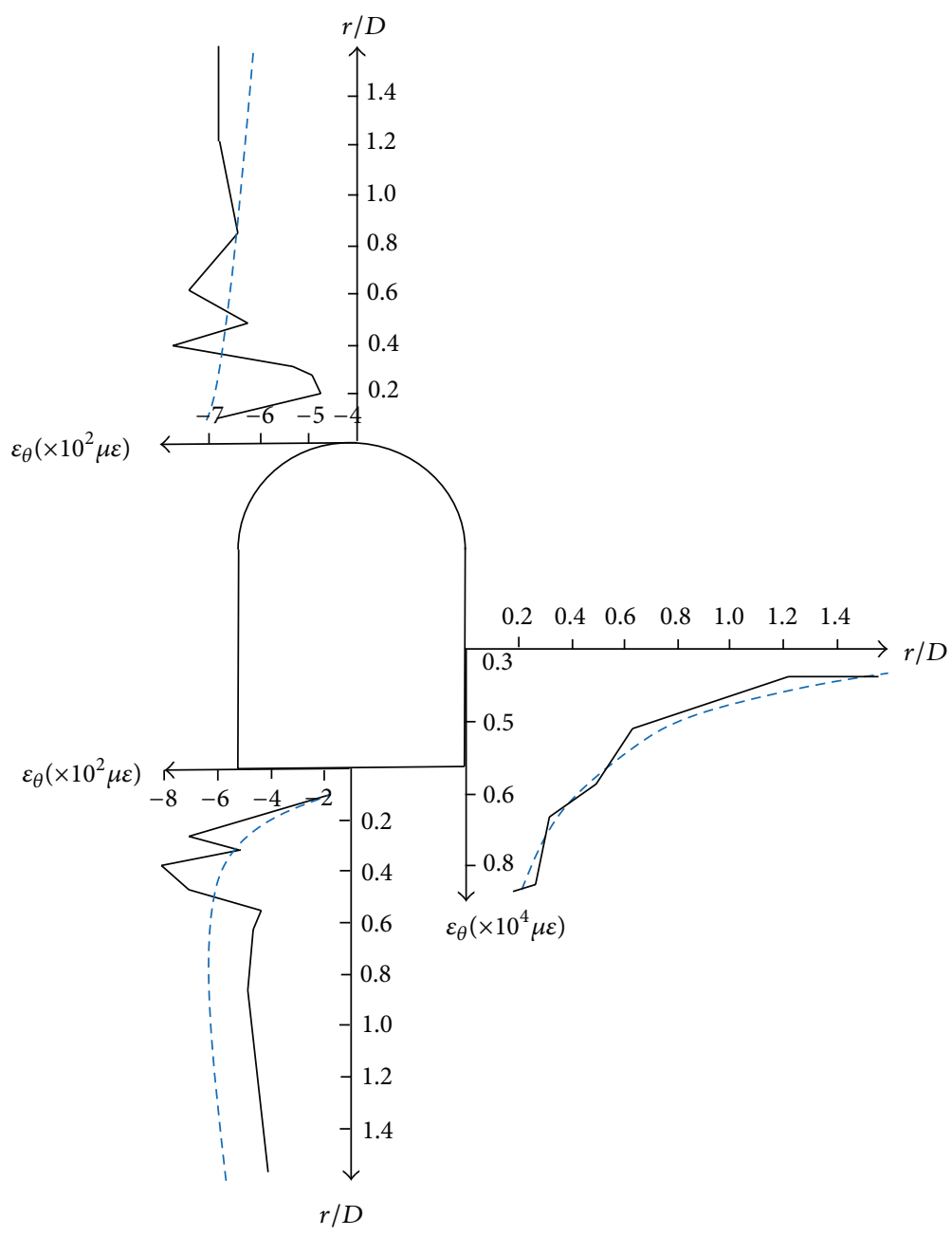

FIGURE 12: Circumferential strain curve of the M2 model cavern.

range of 1.5 times the diameter of the cavern and a failure range of 0.45 times the diameter of the cavern; however, the rock masses of a shallow cavern with the same shape as the deep cavern used in the present study have a tensile failure range of approximately 0.36 times the diameter of the cavern. When designing a support system for rock masses, the strengthening range of anchor rods and anchor cables should be greater than the tensile range of the cavern. Let us take a cavern with a span of $10 \mathrm{~m}$ as an example; the length of the support system for such a cavern should be greater than $15 \mathrm{~m}$. Therefore, the strengthening range of the rock masses of a deep cavern should be far greater than the strengthening range of the rock masses of a shallow cavern.

5.2. Comparison of the Failure Modes. Overall, although there are differences in the ground stress load and the maximum test load between M1 and M2, the macroscopic failure phenomena of M1 and M2 are basically identical. By comparing the macroscopic failure phenomena of $\mathrm{M} 1$ and M2, the differences between M1 and M2 are exposed as follows: (i) The maximum test load of M1 is relatively small; the degree of damage to $\mathrm{M} 1$ is relatively small.

(ii) The cracks along the obliquely downward directions of the left and right sidewalls of M2 are relatively well developed, which, combined with the cracks that have developed upwards from the bottoms of the sidewalls, form relatively significant wedge-shaped cracked bodies.

(iii) After the cracks originate from the bottoms of the left and right sidewalls of $\mathrm{Ml}$, the cracks continue developing upwards and move farther from the sidewalls as the distance from the floor increases; when the cracks have progressed to the locations that are on the same horizontal level with the centers of the sidewalls, the cracks are basically parallel to the sidewalls; in particular, the cracks in the right sidewall do not converge at the foot of the vault. After the cracks originate from the bottoms of the sidewalls of $\mathrm{M} 2$, the cracks also develop upwards as the distance from the floor increases; however, when the cracks encounter the cracks along the obliquely downward directions 


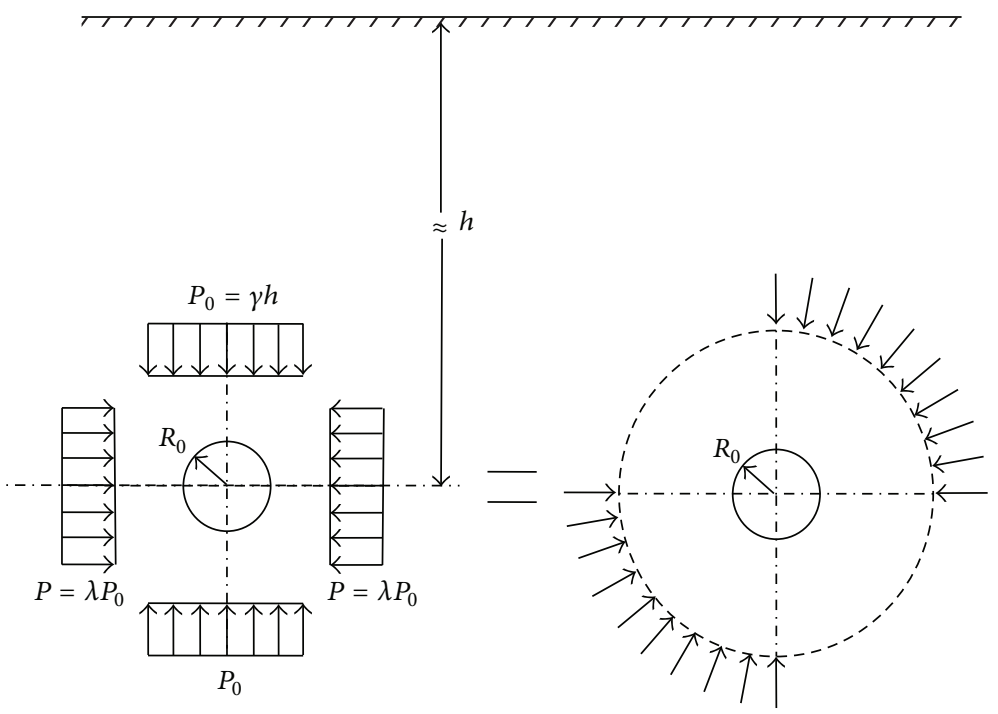

FIgURE 13: Simplified diagram of the forces on a deeply buried cavern.

from the feet of the vault, the cracks that originated at the bottoms of the sidewalls stop developing; only the two outermost cracks do not intersect and continue to develop.

\section{Analysis of the Failure Mechanism}

Figure 13 shows the simplified diagram of the forces on a deeply buried circular cavern. Based on the equilibrium equation, the geometric equation, and the constitutive equation, the solutions of the radial stress, the circumferential stress, and the shear stress at an arbitrary point (such a point is at a distance $r$ away from the center of the cavern; in addition, the angle between the line that connects such a point and the center of the cavern and the rightward horizontal axis is $\theta$ ) are

$$
\begin{aligned}
\sigma_{r}= & \frac{1}{2}(1+\lambda) P_{0}\left(1-\frac{R_{0}{ }^{2}}{r^{2}}\right) \\
& -\frac{1}{2}(1-\lambda) P_{0}\left(1-4 \frac{R_{0}^{2}}{r^{2}}+3 \frac{R_{0}^{4}}{r^{4}}\right) \cos 2 \theta, \\
\sigma_{\theta}= & \frac{1}{2}(1+\lambda) P_{0}\left(1+\frac{R_{0}{ }^{2}}{r^{2}}\right) \\
& +\frac{1}{2}(1-\lambda) P_{0}\left(1+3 \frac{R_{0}{ }^{4}}{r^{4}}\right) \cos 2 \theta, \\
\tau_{r \theta}= & \frac{1}{2}(1-\lambda) P_{0}\left(1+2 \frac{R_{0}{ }^{2}}{r^{2}}-3 \frac{R_{0}{ }^{4}}{r^{4}}\right) \sin 2 \theta .
\end{aligned}
$$

When $r=R_{0}$, that is, at the wall of the cavern,

$$
\begin{aligned}
\sigma_{r} & =\tau_{r \theta}=0, \\
\sigma_{\theta} & =(1+\lambda) P_{0}+2(1-\lambda) P_{0} \cos 2 \theta .
\end{aligned}
$$

Thus, in a circular cavern, there is only a circumferential stress along the periphery of the wall of the cavern; the radial stress and the shear stress are zero; the circumferential stress along the periphery of the wall of the cavern and the distribution of such circumferential stress primarily depend on the side pressure coefficient $(\lambda)$. Because the failure of the rocks surrounding a cavern begins from the wall of the cavern, the distribution of the circumferential stress along the periphery of the wall of the cavern determines the earliest failure point of the cavern; therefore, the circumferential stress along the wall of the M1 model is primarily analyzed in the present study.

The prototype of the present study is a semicircular cavern with straight walls and an arch vault; the prototype cavern has a buried depth of $H=1000 \mathrm{~m}$, a rock mass density of $\rho=$ $2.4 \times 10^{3} \mathrm{~kg} / \mathrm{m}^{3}$, and a specific weight of $\gamma=2.4 \times 10^{4} \mathrm{~N} / \mathrm{m}^{3}$. The key points of the semicircular cavern with straight walls and an arch vault are as follows: number 1 point (the top of the vault), number 2 point (the middle point between the top of the vault and foot of the vault), number 3 point (a foot of the vault), number 4 point (the center of a sidewall), and number 5 point (the bottom of a sidewall) (Figure 14). The calculation equation for the circumferential stresses on the wall of the cavern $\left(\sigma_{\theta}\right)$ is as follows:

$$
\sigma_{\theta}=\gamma(\alpha+\beta \lambda)\left(H^{\prime}+k r_{0}\right),
$$

where $\alpha$ and $\beta$ are calculation coefficients (see Table 4). Based on the aforementioned coefficients, the circumferential stresses at the key points on the walls of the cavern can be obtained (Table 5).

The values listed in the table indicate that after the excavation of the prototype cavern with straight walls and an arch vault is completed, the circumferential compressive stress on the bottom of each sidewall is greatest; the compressive shear failure begins at the bottom of each sidewall, and the cracks that originate from the bottom of each sidewall will gradually extend outwards, which can also be observed in 


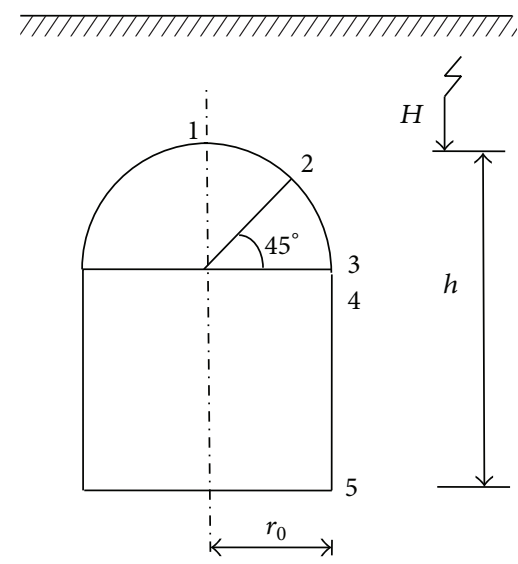

FIGURE 14: Key points of the semicircular cavern with straight walls and an arch vault.

TABLE 4: Calculated coefficients for the circumferential stresses on the periphery of the semicircular cavern with straight walls and an arch vault.

\begin{tabular}{lccccc}
\hline Point numbers & 1 & 2 & 3 & 4 & 5 \\
\hline$\alpha$ & -0.9758 & 0.8131 & 2.1908 & 2.1704 & 3.4704 \\
$\beta$ & 3.2138 & 1.2639 & -0.9001 & -0.7654 & 1.8451 \\
$k$ & & & 1.1145 & & \\
\hline
\end{tabular}

TABLE 5: Values of the circumferential stresses at the key points of the semicircular cavern with straight walls and an arch vault.

\begin{tabular}{lccccc}
\hline $\begin{array}{l}\text { Circumferential } \\
\text { stresses }\end{array}$ & 1 & 2 & 3 & 4 & 5 \\
\hline$\sigma_{\theta}$ & -53.80 & -49.93 & -31.03 & -33.78 & -127.79 \\
\hline
\end{tabular}

the macroscopic failure of and the development of the cracks in M1, indicating that the failure mode of the cavern with straight walls and an arch vault under plane strain conditions that was obtained from the present study is correct and reasonable and in accordance with the actual stress state of a deep cavern.

\section{Conclusions}

The deformation and failure characteristics of deep rock masses are an important component of the research on deep rock mass engineering. In the present study, the deformation and failure characteristics of two deep caverns under different ground stress conditions are derived using the model test method. Using the model test, the failure characteristics of deep caverns and the strain distribution characteristics along the peripheries of the caverns under different ground stress conditions are derived. The test results show that the tensile range of the rock masses of a deep cavern is far greater than the tensile range of the rock masses of a shallow cavern. Under the conditions used in the present study, the rock masses have a tensile range of 1.5 times the diameter of the cavern and a failure range of approximately 0.45 times the diameter of the cavern. When designing a support system for rock masses, the strengthening range of anchor rods and anchor cables should be greater than the tensile range of the cavern.

The research results show that there are differences in the failure characteristics under different ground stress conditions: a cavern with a low cavern-excavation load has a slightly smaller failure range, and the main failure form of a cavern with a low cavern-excavation load is the outward development of fracture cracks from the feet of the walls, while the feet of the vault remain basically intact. Linear sliding failure occurs in both the feet of the vault and the feet of the walls of a cavern with a relatively large cavernexcavation load, and the linear sliding failure at the top and the bottom is approximately symmetrical.

The causes of the differences in the failure characteristics of a deep cavern under different ground stress conditions are analyzed; because of the difference between the pre- and poststress concentration states, the feet of the walls of a cavern with a relatively low cavern-excavation load enter a stress concentration state first; the subsequent load is applied to the cavern that is already in a stress concentration state, resulting in the occurrence of failure at the feet of the walls, which, in turn, results in the occurrence of stress transfer that reduces the damage to the other sections; thus, the failure of a cavern with a relatively small cavern-excavation load is relatively less severe.

\section{Conflict of Interests}

The authors declare no conflict of interests.

\section{Authors' Contribution}

Chong Zhang and Zhechao Wang conceived and designed the experiments; Qi Wang performed the experiments; Chong Zhang and Qi Wang analyzed the data; Zhechao Wang wrote the paper.

\section{Acknowledgments}

The present study was supported by the general projects of the National Natural Science Foundation of China (Grant no. 51474095). The authors hereby wish to express their gratitude.

\section{References}

[1] R. S. Read, "20 years of excavation response studies at AECL's underground research laboratory," International Journal of Rock Mechanics and Mining Sciences, vol. 41, no. 8, pp. 1251-1275, 2004.

[2] Q. H. Qian, "The characteristic scientific phenomena of engineering response to deep Rock mass and the implication of deepness," Journal of East China Institute of Technology, vol. 27, no. 1, pp. 1-5, 2004 (Chinese).

[3] M. C. He, H. P. Xie, S. P. Peng, and Y. D. Jiang, "Study on rock mechanics in deep mining engineering," Chinese Journal of Rock Mechanics and Engineering, vol. 24, no. 16, pp. 2803-2813, 2005 (Chinese).

[4] J. C. Gu, L. Y. Gu, A. M. Chen, J. Xu, and W. Chen, "Model test study on mechanism of layered fracture within surrounding 
rock of tunnels in deep stratum," Chinese Journal of Rock Mechanics and Engineering, vol. 27, no. 3, pp. 433-438, 2008 (Chinese).

[5] X. P. Zhou and Q. H. Qian, "Zonal fracturing mechanism in deep tunnel," Chinese Journal of Rock Mechanics and Engineering, vol. 26, no. 5, pp. 877-885, 2007 (Chinese).

[6] S. C. Li, H. P. Wang, Q. H. Qian et al., "In-situ monitoring research on zonal disintegration of surrounding rock mass in deep mine roadways," Chinese Journal of Rock Mechanics and Engineering, vol. 27, no. 8, pp. 1545-1553, 2008 (Chinese).

[7] E. I. Shemyakin, G. L. Fisenko, M. V. Kurlenya et al., "Zonal disintegration of rocks around underground workings, Part 1: data of in situ observations," Soviet Mining Science, vol. 22, no. 3, pp. 157-168, 1986.

[8] M. A. Guzev and A. A. Paroshin, "Non-Euclidean model of the zonal disintegration of rocks around an underground working," Journal of Applied Mechanics and Technical Physics, vol. 42, no. 1, pp. 131-139, 2001.

[9] L. S. Metlov, A. F. Morozov, and M. P. Zborshchik, "Physical foundations of mechanism of zonal rock failure in the vicinity of mine working," Journal of Mining Science, vol. 38, no. 2, pp. 150-155, 2002.

[10] V. N. Reva, "Stability criteria of underground workings under zonal disintegration of rocks," Fiziko-Tekhnicheskie Problemy Razrabotki Poleznykh Iskopaemykh, no. 1, pp. 35-38, 2002.

[11] M. S. Diederichs, P. K. Kaiser, and E. Eberhardt, "Damage initiation and propagation in hard rock during tunnelling and the influence of near-face stress rotation," International Journal of Rock Mechanics \& Mining Sciences, vol. 41, no. 5, pp. 785-812, 2004.

[12] X. P. Zhou, Q. H. Qian, B. H. Zhang et al., "The mechanism of the zonal disintegration phenomenon around deep spherical tunnels," Engineering Mechanics, vol. 27, no. 1, pp. 69-75, 2010 (Chinese).

[13] S. C. Li, Q. H. Qian, D. F. Zhang et al., "Analysis of dynamic and fractured phenomena for excavation process of deep tunnel," Chinese Journal of Rock Mechanics and Engineering, vol. 28, no. 10, pp. 2104-2112, 2009 (Chinese).

[14] Y. J. Li, Y. S. Pan, and Z. H. Li, "Analysis of mechanism of zonal disintegration of rocks," Chinese Journal of Geotechnical Engineering, vol. 28, no. 9, pp. 1124-1128, 2006 (Chinese).

[15] M. C. Liao, Z. K. Guo, and F. Liu, "Determination of the specimen size for model experiment on zonal fracturing of deep rock mass," Journal of Disaster Prevention and Mitigation Engineering, vol. 26, no. 1, pp. 58-62, 2006 (Chinese). 


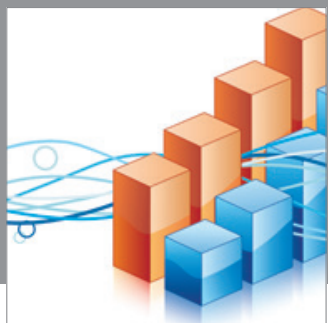

Advances in

Operations Research

mansans

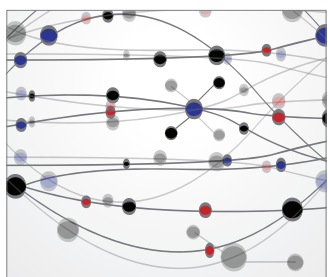

The Scientific World Journal
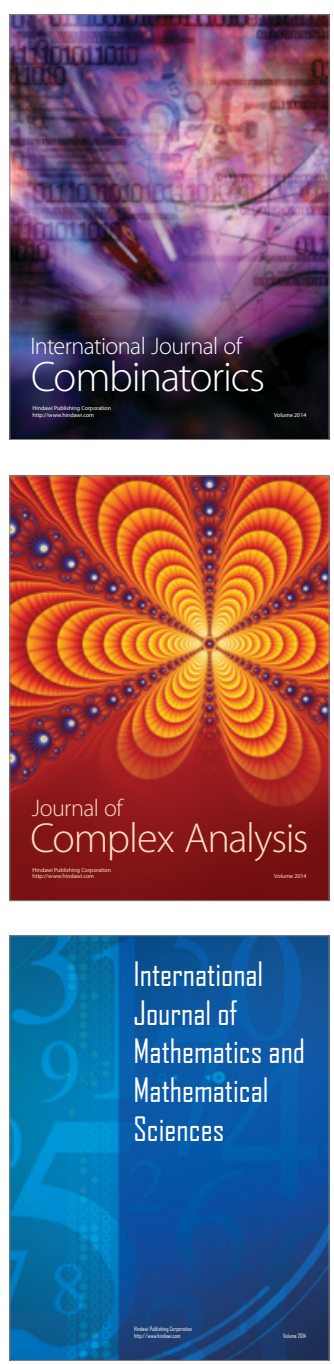
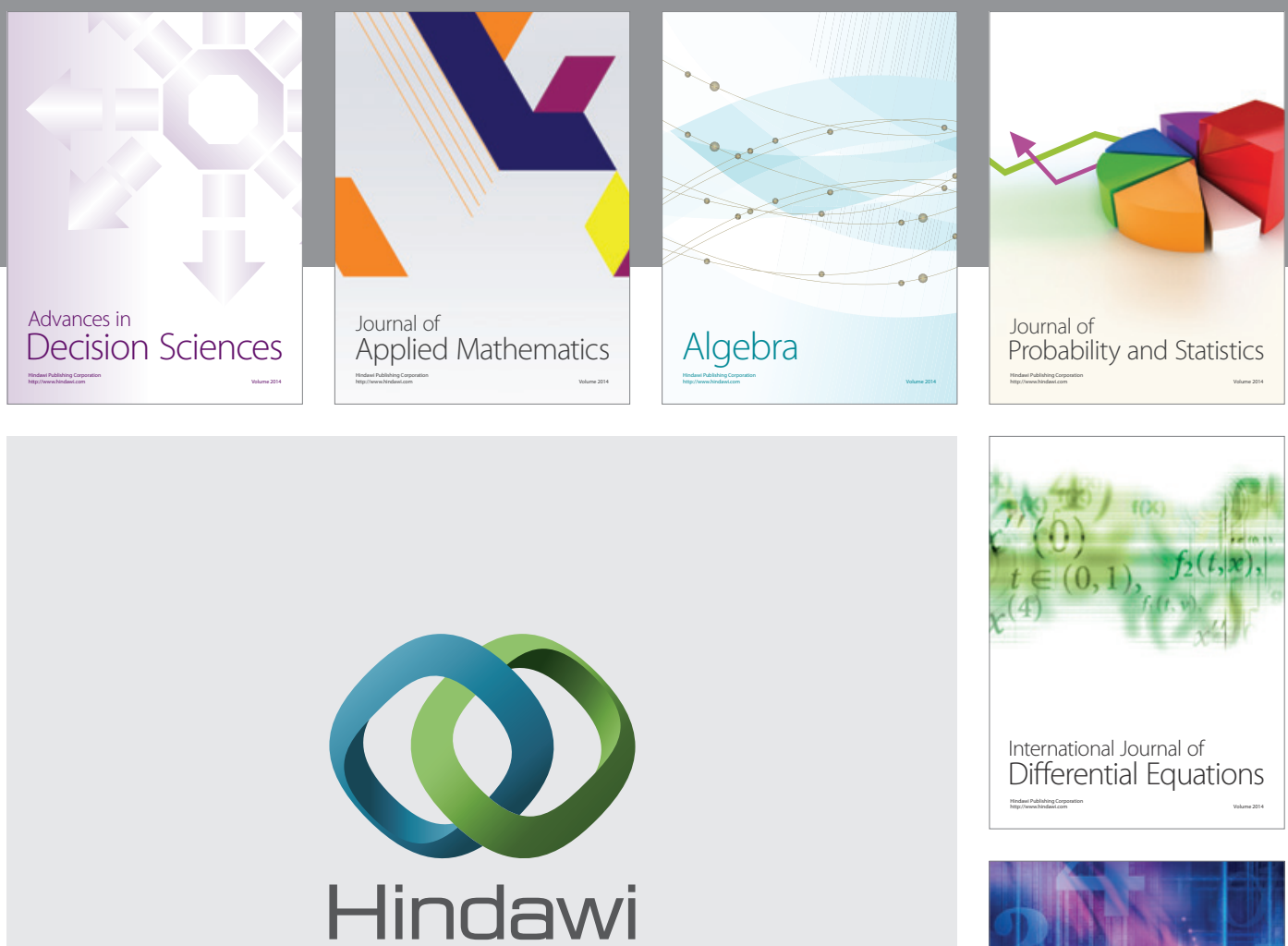

Submit your manuscripts at http://www.hindawi.com
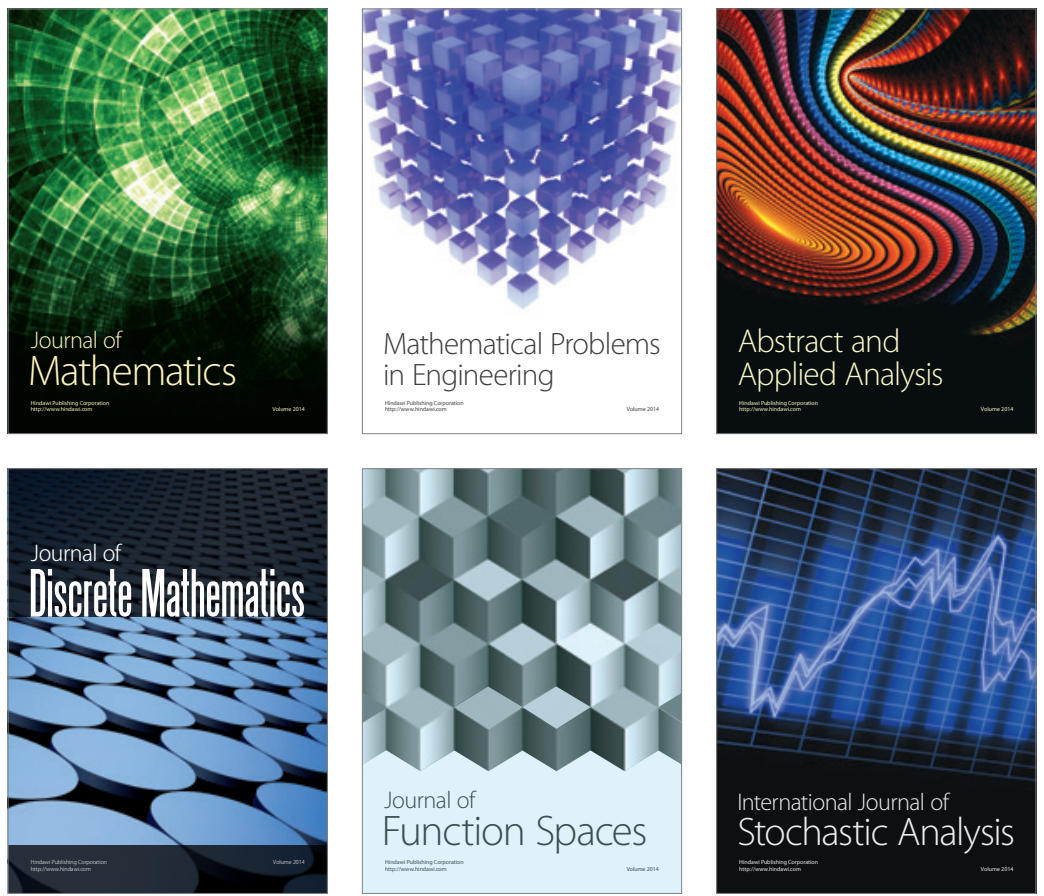

Journal of

Function Spaces

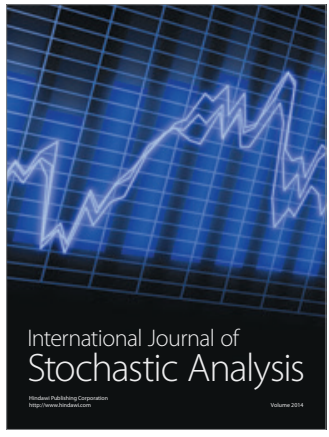

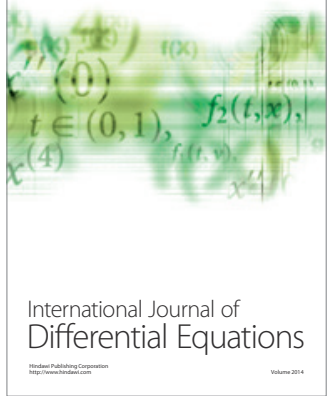
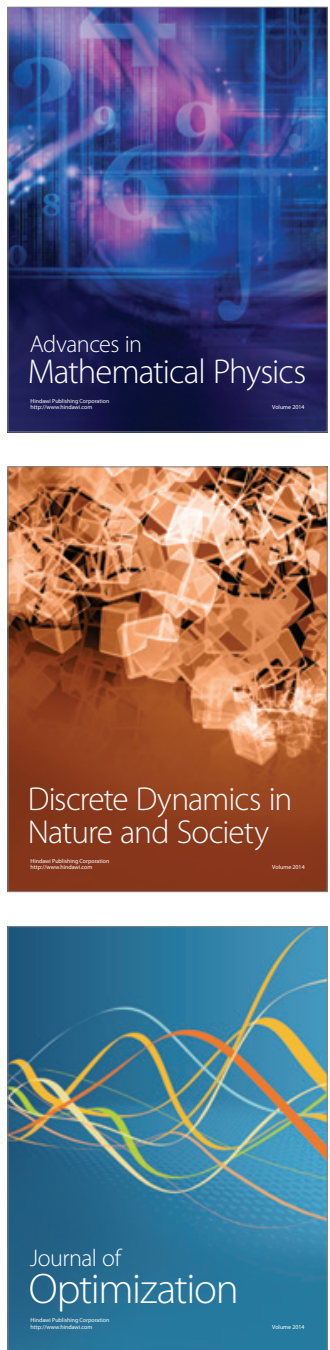